\title{
Verification of the reinforced concrete column bar model based on the test results
}

\author{
Oleg Mkrtychev, Marina Dudareva* and Mikhail Andreev \\ Moscow State University of Civil Engineering, Yaroslavskoe shosse, 26, Moscow, 129337, Russia
}

\begin{abstract}
Modern software packages for calculating buildings and structures for various types of action make it possible to simulate the structure and its elements in sufficient detail and to reflect adequately the behavior of this structure. However, detailed simulation with the use of solid finite elements requires a large amount of computing time to perform calculations. This problem can be solved by moving from solid finite elements to bar elements. At the same time, it is necessary to verify the bar calculation models. The article compares the calculation results of a reinforced concrete column simulated in two ways: with the use of solid finite elements based on the actual reinforcement and with the use of bar finite elements. The concrete material for the reference model is specified using a Continuous Surface Cap Model nonlinear model implemented in the LS-DYNA software package. This model reflects the non-linear behavior of concrete and enables to consider the joint behavior of concrete and reinforcing bars. The diagrams of concrete behavior in the bar model are adopted in accordance with SP 63.13330.2012 "Concrete and reinforced concrete structures. Revised edition of SP 52-101-2003". The study compares the results obtained by the breaking load value and the fracture pattern of the column under consideration.
\end{abstract}

\section{Introduction}

Design of unique buildings and structures requires the scientific and technical support. In this case, calculations of multielement systems, as a rule, are carried out considering physical and geometric nonlinearities $[1,2]$. Such an approach significantly increases the time of such calculations, there are difficulties associated with the choice of the type of finite elements and models of materials.

Recently there has been a tendency to introduce into the software packages (especially domestic) the solid finite elements, which, when simulating structural elements, most adequately reflect their behavior [3]. However, in the calculation of multi-element systems, this factor will require massive computing power and increase in the calculation time, which will have a critical impact on the design time.

\footnotetext{
* Corresponding author: marina8busalova@gmail.com
} 
In this case, many nonlinear models of materials, applied mainly to solid finite elements and adequately reflecting the behavior of the material under load, cannot be applied to bar models [4].

That is why in order to optimize the timing of calculations of buildings and structures it is required to verify behavior both structural elements and materials.

\section{Methods}

A reinforced concrete column with a height of $1.15 \mathrm{~m}$, with square cross-section of $\varnothing 12$, $0,15 \times 0,15 \mathrm{~m} \mathrm{~mm}$ longitudinal reinforcing bars and $\varnothing 6 \mathrm{~mm}$ cross clamps was considered as an object of study. Figure 1 shows the loading diagram of this column, the concrete of which was modeled by solid finite elements (Fig. 1a), and the reinforcement - by rod finite elements (Fig. 1b). Concrete material was specified using a Continuous Surface Cap Model nonlinear model, which enables to consider the joint behavior of concrete and reinforcing bars $[4,5]$. Figure 2 shows the bar model of the column under consideration.

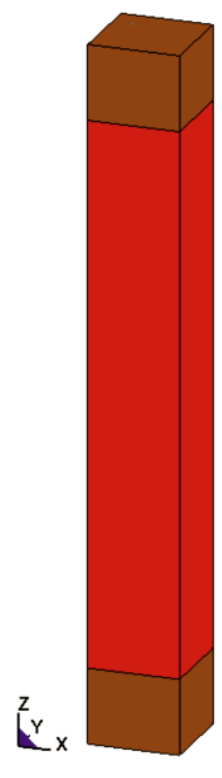

a)

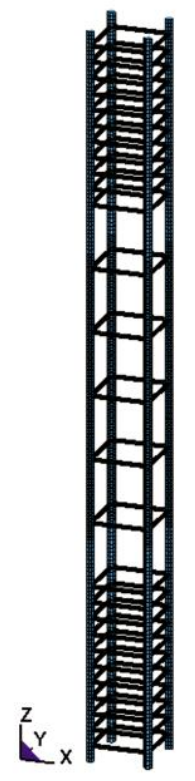

b)

Fig.1. Loading diagram of a reinforced concrete column modeled by solid finite elements a) concrete elements; b) reinforcement cage. 


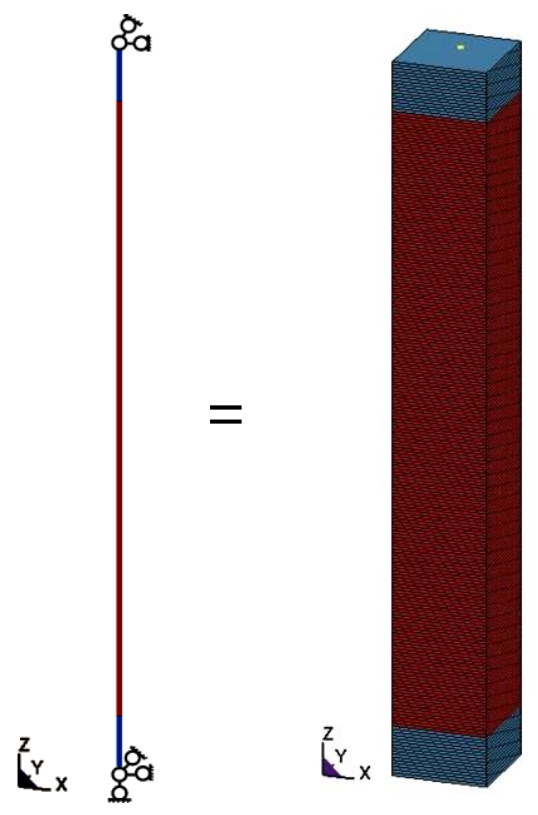

Fig.2. Loading diagram of a reinforced concrete column simulated by rod finite elements.

Fixing conditions, load, and material characteristics for the reference column were assumed in accordance with the experimental data described in [6]. The authors of this article studied behavior of the column under consideration, loaded with eccentrically compressive force, and compared their results with the results of the experiment mentioned [6]. A fairly good convergence of the results (breaking force values, fracture pattern) allowed us to consider this model as a reference model for verification purposes.

In the case of the bar model, the calculation was carried out for two different formulations. The concrete behavior diagrams for each case were assumed in accordance with SP 63.13330.2012 "Concrete and reinforced concrete structures. Revised edition of SP 52-101-2003." [7] (Figure 3).

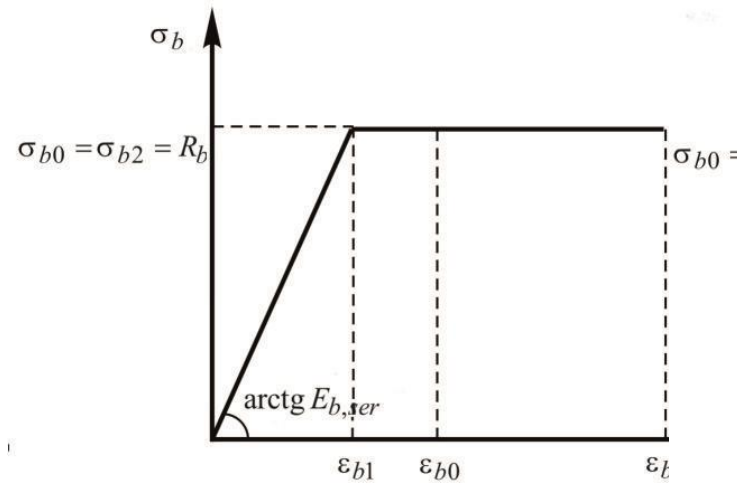

a)

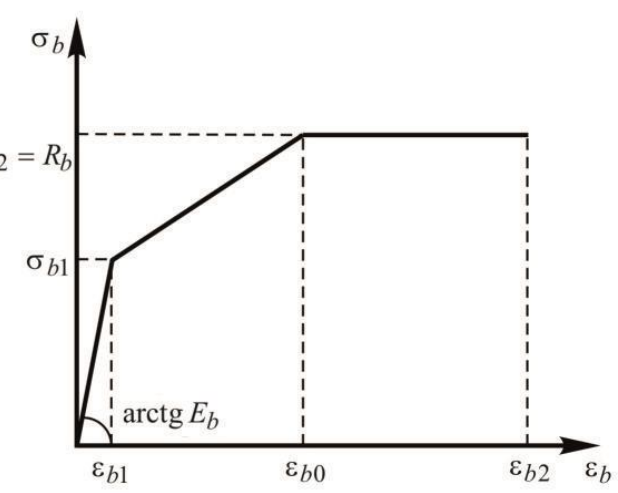

b)

Fig.3. Concrete behavior diagram a) bilinear; b) trilinear.

When testing structural elements, the parameters of the material of the test specimens are determined by their average values, in particular, by the average strength. However, when designing building structures according to the current regulatory document [7], the calculation should consider the calculated values of this characteristic, with a given 
occurrence [7]. In this case, the actual design strength is underestimated by about 1.5 times. That is why in the verification process, two calculation tasks were considered: in the first formulation, the concrete parameters were assumed in accordance with the norms [7], in the second formulation, the average strength corresponding to the considered grade of concrete was specified [8].

Numerical experiments were carried out with the use of the LS-DYNA software package. The results obtained were evaluated by comparing the breaking load values and the fracture pattern of the column under consideration. Below are the main results of the calculation.

\section{Results}

Figure 4 shows intensity isofields of plastic deformations, both in concrete elements and in reinforcing bars for the reference model. In this case, the ultimate breaking load is $\mathrm{P}=$ $587.5 \mathrm{kN}$.

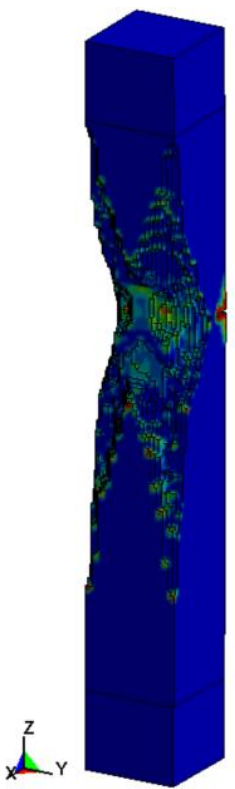

a)

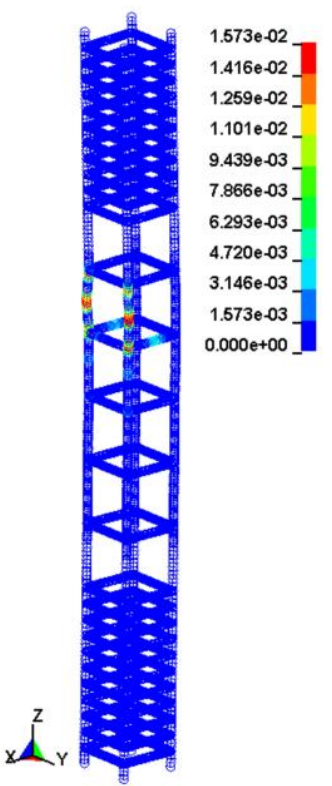

b)

Fig.4. Intensity isofields of plastic deformations in the reference model a) concrete elements; b) reinforcing bars. Ultimate breaking load $\mathrm{P}=587.5 \mathrm{kN}$.

For comparison, Figures $5 \mathrm{a}$ and $5 \mathrm{~b}$ show intensity isofields of plastic deformations in the bar model for the two loading cases considered. 


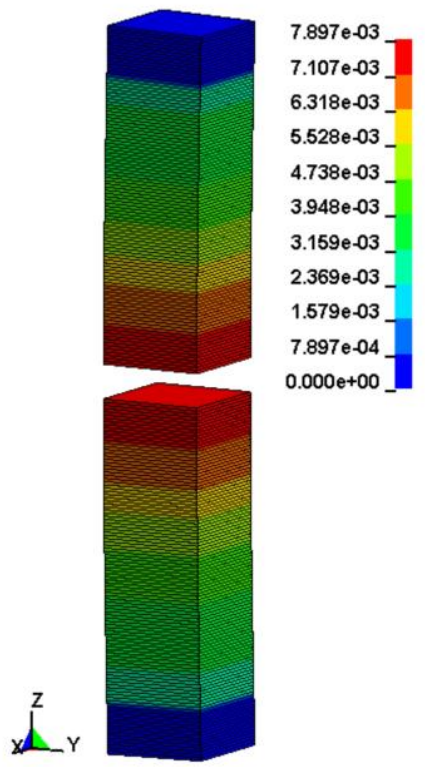

a)

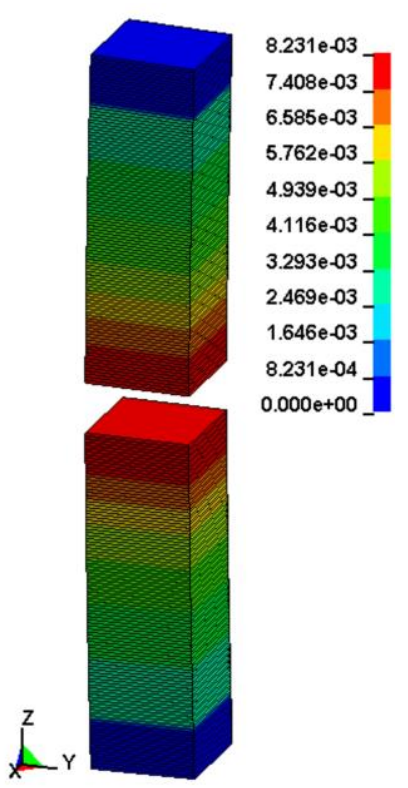

b)

Fig.5. Intensity isofields of plastic deformations in the bar model a) calculated strength value. Ultimate breaking load $\mathrm{P}=262.5 \mathrm{kN}$; b) average strength value. Ultimate breaking load $\mathrm{P}=431.25 \mathrm{kN}$.

The results obtained show that the fracture pattern of the column coincides with the fracture pattern of the reference model, but there is a certain difference in the magnitude of the ultimate breaking load (Table 1).

Table 1. Comparison of ultimate breaking load values.

\begin{tabular}{|c|c|c|}
\hline Model & $\begin{array}{c}\text { Ultimate breaking load value, } \\
\text { kN }\end{array}$ & Discrepancy, \% \\
\hline Reference model & 587.5 & - \\
\hline $\begin{array}{c}\text { Bar model } \\
\text { calculated } \\
\text { strength) }\end{array}$ & 262.5 & 55 \\
\hline $\begin{array}{c}\text { Bar model (average } \\
\text { strength) }\end{array}$ & 431.25 & 26.6 \\
\hline
\end{tabular}

\section{Discussion}

In $[6,9]$, the results of full-scale tests of elements of building structures are compared with the results of numerical studies in which the main finite elements for concrete are solid finite elements, for reinforcing bars - bar finite elements. There is a good convergence of calculation results with experimental data. Thus, behavior of the elements of building structures is well described by simulating with the use of solid finite elements. However, as noted above, this entails significant time costs.

The results of numerical studies carried out in this work indicate that the use of the bar model to calculate the effect of the eccentrically compressive force for the reinforced concrete column in this formulation is incorrect (Table 1). In [10], verification of the reinforced concrete beam bar model for the effect of a distributed load was performed. According to the results of verification, it was established that the use of a beam 
mathematical model in the form of bar elements is permissible, but only with the assumption of "optimal" reinforcement. However, for other reinforcement cases such simulation is also incorrect.

\section{Conclusions}

The analysis of the results of the verification of the reinforced concrete column simulated by bar elements, considering the nonlinear pattern of its deformation suggests that traditional approaches are not applicable to calculation in a linear elastic formulation. When moving from solid elements to bars, mandatory verification of the calculation bar model and development of methods for accounting for the reinforcement of load-bearing elements of building structures modeled by the bar finite elements are necessary. In this paper, this verification was carried out for a reinforced concrete column.

This study was performed with the financial support of the RF Ministry of Education and Science, grant \#7.1524.2017/Project Part.

\section{References}

1. SP 14.13330.2014 SNIP II-7-81. Construction in Seismic Areas (Analitik, Moscow, 2014)

2. O. Mkrtychev, G. Dzhinchvelashvili, M. Busalova MATEC WoC 86, 01018 (2016)

3. O. Mkrtychev, M. Busalova Proc. Eng. 153, 475-482 (2016)

4. Y. D. Murray, Users Manual for LS-DYNA Concrete Material Model 159 (Federal Highway Administration, 2007)

5. O. Mkrtychev, M. Busalova Adv. Eng. Res. 104, 160-164 (2016)

6. J. Nemecek, P. Padevet, Z. Bittnar Acta Pol. 44, 158-164 (2004)

7. SP 63.13330.2012 Concrete and Reinforced Concrete Structures. Summary (2012)

8. O. Mkrtychev, D. Sidorov, S. Bulushev MATEC WoC 117, 00123 (2017)

9. O. Mkrtychev, M. Andreev MATEC WoC 196, 01029 (2018)

10. O. Mkrtychev, M. Busalova, V. Dorozhinskiy MATEC WoC 117, 00124 (2017) 